\title{
Scopolamine Hydrobromide
}

National Cancer Institute

\section{Source}

National Cancer Institute. Scopolamine Hydrobromide. NCI Thesaurus. Code C29446.

The hydrobromide salt form of scopolamine, a tropane alkaloid derived from plants of the nightshade family (Solanaceae), specifically Hyoscyamus niger and Atropa belladonna, with anticholinergic, antiemetic and antivertigo properties. Structurally similar to acetylcholine, scopolamine antagonizes acetylcholine activity mediated by muscarinic receptors located on structures innervated by postgang lionic cholinergic nerves as well as on smooth muscles that respond to acetylcholine but lack cholinergic innervation. The agent is used to cause mydriasis, cycloplegia, to control the secretion of saliva and gastric acid, to slow gut motility, and prevent vomiting. 